\title{
What we (don"t) know about the effects of habitat loss and fragmentation on felids
}

\author{
Marina Zanin, Francisco Palomares and Daniel Brito
}

\begin{abstract}
Felid species have intrinsic ecological traits that make them particularly susceptible to the threats of habitat loss and fragmentation. We collate current knowledge of the effects of habitat loss and fragmentation on felids, describing trends, investigating the allocation of research effort and identifying knowledge gaps. We searched the scientific literature and categorized articles according to conceptual and methodological approaches. We reviewed 162 articles and observed that scientific knowledge is unevenly distributed among topics and species. Habitat suitability and patch-landscape configuration are the most studied topics. The allocation of research effort is unrelated to variables that describe conservation priorities, such as threat status and habitat availability within a species' range, but it is related to body size, suggesting that charismatic attributes influence the choice of target species. Countries with less research effort are also those with less economic development, and thus North America and Europe are the centres of knowledge generation of reviewed studies. The responses of sixteen felid species to habitat loss and fragmentation remain unknown. Of these the Andean mountain cat Leopardus jacobita, the Bornean bay cat Pardofelis badia, the flat-headed cat Prionailurus planiceps and the fishing cat Prionailurus viverrinus most urgently require research because they are threatened with extinction. We recommend the use of theoretical approaches, through modelling exercises, as a first step to address the lack of information about the effects of habitat loss and fragmentation on felids, especially for those species for which there are large knowledge gaps.
\end{abstract}

Keywords Felidae, fragmentation, gap analysis, habitat loss, landscape, metapopulation

This paper contains supplementary material that can be found online at http://journals.cambridge.org

MARINA ZANIN (Corresponding author) Departamento de Ecologia, Universidade Federal de Goiás, Caixa Postal 131, CEP 74001-970, Goiania, Goiás, Brazil. E-mail marinazaning@gmail.com

Francisco Palomares Department of Conservation Biology, Estación Biológica de Doñana CSIC, Seville, Spain

DANiEL BRito Departamento de Ecologia, Universidade Federal de Goiás, Goiania, Brazil

Received 15 May 2013. Revision requested 16 September 2013.

Accepted 26 November 2013. First published online 11 August 2014.

\section{Introduction}

7 he rate of habitat loss and fragmentation is increasing 1 as a result of human activities that convert natural landscapes into human-modified mosaics (Lord \& Norton, 1990; Riitters et al., 2000). Habitat loss and fragmentation reduce the availability of suitable habitat for wildlife, create dispersion barriers and affect the size and spatial configuration of habitat areas (Fahrig, 1997; Ewers \& Didham, 2006) at local (Lord \& Norton, 1990) and global scales (Riitters et al., 2000). They are considered the main threats to biodiversity (Foley et al., 2005), and many reviews and meta-analyses have been published, with the objective of clarifying terms (e.g. Andrén, 1994; Fahrig, 2003; Fischer \& Lindenmayer, 2007), methodological aspects (Debinski \& Holt, 2000; McGarigal \& Cushman, 2002) and ecological processes (Jenkins et al., 2007; Watling et al., 2011) and effects on target taxa (Mortelliti et al., 2010).

Susceptibility of a species to alteration of the environment is related to life-history and ecological traits (Davidson et al., 2009; Öckinger et al., 2010; Thornton et al., 2011), and therefore it is expected that certain evolutionary lineages are more vulnerable than others to habitat loss and fragmentation. Felids (Carnivore: Felidae) are a phylogenetically and ecologically homogeneous group comprising 36 wild species (Johnson et al., 2006; Morales \& Giannini, 2010). These species share traits that potentially make them vulnerable to habitat loss and fragmentation, such as a high trophic level, large home range and low population density (Sunquist \& Sunquist, 2002), and they are subject to continued persecution by humans (Woodroffe \& Ginsberg, 1998; Inskip \& Zimmermann, 2009). Felids are an interesting model for studying the effects of habitat loss and fragmentation on wildlife populations because of their susceptibility to such effects, their key ecological roles within ecosystems and their charisma.

Our objective was to review the literature on the effects of habitat loss and fragmentation on felids, investigating biases and trends in knowledge. Here we chart the state of knowledge concerning the effects of habitat loss and fragmentation on felids, discussing weaknesses in methodology and concept, and potential solutions to correct such weaknesses. We identify the allocation of research effort across species and countries; we chose these taxonomic and geopolitical scales because they are the levels at which conservation actions are generally planned and implemented. We expect 
TABLE 1 Definitions of terms used.

\begin{tabular}{|c|c|}
\hline Term & Definition \\
\hline \multicolumn{2}{|l|}{ Process evaluated } \\
\hline Habitat reduction & Loss in the total area of habitat available to a species \\
\hline Habitat subdivision & Habitat partition into smaller patches \\
\hline Buildings as barrier & $\begin{array}{l}\text { Unnatural barriers (such as roads, dams, urban areas) that make animal movement } \\
\text { in the landscape difficult }\end{array}$ \\
\hline Habitat loss by climate change & $\begin{array}{l}\text { Reduction of the total area of habitat available to a species as a result of the increase } \\
\text { in mean global temperature }\end{array}$ \\
\hline \multicolumn{2}{|l|}{ Approach } \\
\hline Review & A survey about a particular subject \\
\hline Empirical & Use of observed data to report a result \\
\hline Theoretical & Use of a simulated environment \& database to investigate a pattern or test a hypothesis \\
\hline \multicolumn{2}{|l|}{ Sub-discipline } \\
\hline Conservation medicine & Investigates wildlife health in response to anthropogenic pressure \& habitat conversion \\
\hline Demographic viability & $\begin{array}{l}\text { Investigation of population viability through the number of individuals in a population } \\
\text { or metapopulation }\end{array}$ \\
\hline Genetic viability & $\begin{array}{l}\text { Investigation of population viability through the genetic diversity of a population } \\
\text { or metapopulation }\end{array}$ \\
\hline Habitat selection & $\begin{array}{l}\text { Evaluation of habitat suitability through the hierarchy of space, which can be based } \\
\text { on variegation or contour models }\end{array}$ \\
\hline Landscape genetics & The influence of the landscape on gene flow \& spatial genetic variation \\
\hline Movement ecology & $\begin{array}{l}\text { Concerned with the movement of an organism in a landscape, dispersal ability, } \\
\& \text { its choice of non-optimal habitats }\end{array}$ \\
\hline Patch-landscape configuration & $\begin{array}{l}\text { Measure habitat loss \& fragmentation effects on species through the use of fragmentation } \\
\text { metrics }\end{array}$ \\
\hline Road ecology & Road network effects on wildlife \\
\hline Systematic conservation plan & Selection of priority areas for species conservation through systematic planning \\
\hline
\end{tabular}

threatened species to be better studied, with more extensive studies of species for which there are high rates of habitat reduction. However, charismatic attributes and logistical factors could be influencing the choice of target felid species, resulting in a greater focus on large-bodied and widespread species. We expect greater research effort in more developed countries, with research in less-developed countries being led mainly by investigators from developed countries. Based on our results we created an index for the ranking of species according to the lack of information about them.

\section{Methods}

\section{Trends in knowledge}

We searched the scientific literature for articles that quantify or describe effects of habitat loss and fragmentation on felids, using a combination of search strings in three databases: ISI Web of Science, Cat Library, and Google Scholar. For habitat loss and fragmentation we used “'fragmentation' OR 'habitat fragmentation' OR 'habitat loss' OR 'habitat destruction' OR 'habitat alteration' OR 'human alteration"”. For taxonomic groups we used “'mammal' OR 'mammalia' OR 'carnivore' OR 'felid' OR 'feline' OR 'Felidae”. The search strings for individual species are provided in Supplementary Table S1, with the articles located. All articles published up to and including November 2012 were analysed and categorized according to their conceptual and methodological information. We based this categorization on key points in a review of European mammals by Mortelliti et al. (2010), modified for felids.

The key points were (1) the effort dedicated to study the effects of habitat loss and fragmentation on felids (expressed as total number of publications), if the studies measured these effects directly (i.e. they had a clear hypothesis or objective regarding effects of habitat loss and fragmentation on felids, and used explanatory variables to measure such processes within a statistical framework), and temporal trends; (2) taxonomic level; (3) characteristics of habitat loss and fragmentation evaluated (habitat reduction or subdivision, buildings as barriers, climatic changes; Table 1); (4) methodological approach (review, theoretical, empirical; Table 1); (5) ability to separate habitat loss from fragmentation; and (6) sub-discipline (conservation medicine, demographic viability, genetic viability, habitat selection, landscape genetics, movement ecology, patch-landscape configuration, road ecology, systematic conservation plan; see Table 1 for definitions). Poaching of felids or their prey was not included.

To investigate temporal trends in the publications located we divided the number of articles on the effects of 
habitat loss and fragmentation on felids by the total number of articles published each year, assessing the relative growth of knowledge in this area relative to the advancement of science in general. We used the annual total number of articles indexed in ISI Web of Science as an estimate of the annual total number of publications.

\section{Allocation of research effort}

We investigated whether research effort was allocated across species by threat status (IUCN, 2011), body size (Wilson \& Reeder, 2005), range (IUCN, 2011) and suitable habitat within the species' range. The suitable habitat available within the species' range was represented using two variables, the absolute area of suitable habitat and the proportion of the range holding suitable habitat, because a species could have a large absolute area of remaining habitat but also a low proportion of habitat within its range. The proportion of suitable habitat was calculated as the area of suitable habitat inside the range relative to the total range size. We considered as suitable habitat types those listed by IUCN (2011) and calculated the total area from available land-cover maps (ESA, 2011).

We used analysis of covariance (ANCOVA) to evaluate whether the number of publications was equally distributed among species of different threat status, measuring and controlling the effect of body size, range, and suitable habitat within the species' range. Research effort by country was measured in two ways: the proportion of felids studied relative to the number of species in the country, and the proportion of the range studied. We mapped the study areas to identify their distribution. We delineated species ranges with a 0.25 decimal degree grid, and selected grid cells that overlapped with study areas, creating a presence and absence matrix of studies. Using this matrix we calculated the number of species and the area studied in each country; the number of felid species and range area were calculated using species distribution maps (IUCN, 2011).

We categorized economic development based on annual gross national income per capita (World Bank, 2010): $\leqslant 10$, $>10, \leqslant 30$ and $>30$ times the income needed to live at the poverty line (USD 540.5 per person per year; Ravallion et al., 2009). We compared the research effort variables to the economic development categories using non-parametric methods; a Kruskal-Wallis test was used to evaluate the mean variation among groups and a Nemenyi test to identify groups. The Nemenyi test is analogous to the Tukey test for non-parametric analysis, for a posteriori comparison of the groups (Zar, 2010). To investigate the influence of researchers from developed countries we categorized publications based on the gross national income of the target country, the gross national income of the country of the first author and that of the author from the country with the highest gross national income.

\section{Gap analysis}

To clarify the information needed for planning conservation we investigated gaps in knowledge of the effects of habitat loss and fragmentation on felids. We considered the number of publications on relevant topics and ranked these for each species using an index. The knowledge-gap index (KG) was measured as the sum of knowledge distance, calculated as the difference between the total number of articles on a given topic and the number of articles on the same topic for a particular species. The variables were linearly transformed $(0-1)$ to have the same weight in the index, which was calculated as:

$$
K G=\sum_{i=1}^{n} 1-\left(\frac{x_{i j}}{x_{j \max }}\right)
$$

where $i$ are felid species and $j$ are the key points to be considered, which are identified in our results. We considered only articles that were specifically focused on the effects of habitat loss and fragmentation on felids, and calculated the knowledge gap for each species.

To rank species according to their priority for study we included in this index other factors relevant to the knowledge and conservation of each species:

$$
\begin{gathered}
K G_{P R}=\left(\sum_{i=1}^{n} 1-\left(\frac{x_{i j}}{x_{j \text { max }}}\right)\right) P R \\
K G_{T S}=\left(\sum_{i=1}^{n} 1-\left(\frac{x_{i j}}{x_{j \max }}\right)\right) T S \\
K G_{P R / T S}=\left(\sum_{i=1}^{n} 1-\left(\frac{x_{i j}}{x_{j \max }}\right)\right) P R \times T S
\end{gathered}
$$

where $\mathrm{PR}$ is the proportion of the species' range that has not been studied and TS is the species' threat status. PR accounts for the spatial knowledge gap and provides an indirect indicator of the regions or populations not yet studied. We attributed values to TS according to IUCN Red List categorization (Least Concern, 0.2; Near Threatened, 0.4; Vulnerable, o.6; Endangered, o.8; Critically Endangered, 1.0). Equation 4 considers both the proportion of range studied and the threat status, to provide a final ranking of the knowledge gap for a particular topic.

\section{Results and discussion}

\section{Trends in knowledge}

We found 162 published articles concerning the effects of habitat loss and fragmentation on felids (Supplementary Table $\mathrm{S}_{1}$ ). This is a relatively small number considering the number and charisma of felid species and the threat that these processes represent. An analysis of the objectives and 


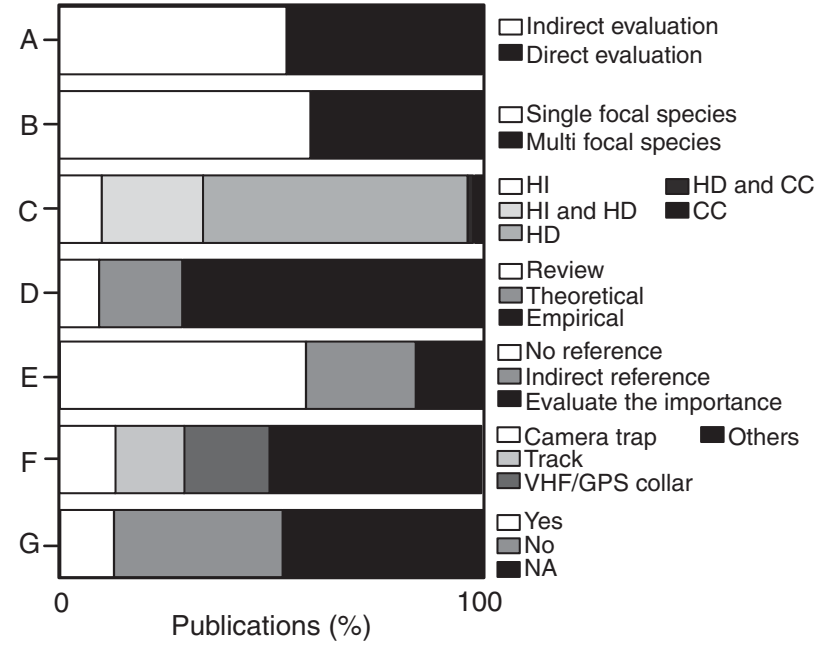

Fig. 1 Percentage of published articles $(n=162)$ on the effects of habitat loss and fragmentation on felid species, categorized according to the study approaches used. A, articles that evaluated indirectly or directly the effects of habitat loss and

fragmentation; B, number of target species investigated; C, studies evaluating the influences of human infrastructure (roads, dams, buildings and other physical barriers; HI) and its effect on habitat destruction (HD), and habitat loss as a result of climatic change (CC); D, methodological approach to investigating the effects of habitat loss and fragmentation; E, inference about dispersion corridors for the conservation of felids in fragmented landscapes (No inference: no reference made to this issue; Indirect inference: mentioned the importance but did not test it; Evaluate the importance: made direct inferences about dispersal corridors); $F$, methods of data sampling; G, differentiation between habitat loss and habitat fragmentation (NA represents articles for which this differentiation is not applicable to the research objectives).

methodologies of these studies reveals that more than half of them address the issue of habitat loss and fragmentation only indirectly (Fig. 1), and therefore we conclude that the knowledge of the effects of habitat loss and fragmentation on felids is limited, even though they are among the most studied mammal groups (Amori \& Gippoliti, 2000).

Although habitat loss and fragmentation has been a popular theme for conservation research since the 1970 s (Haila, 2002), the first publications on its effects on felids did not appear until the early 1990s (Ferreras et al., 1992; Rodríguez \& Delibes, 1992). However, the number of publications has increased (Fig. 2).

Taxonomic level of analysis Most articles considered only one species (Fig. 1). However, for $61 \%$ of felid species such an approach has not been used to study the effects of habitat loss and fragmentation (Fig. 3). Rather, the focus of the research was on carnivores (13.9\%) or mammals in general (19.6\%). Only two studies investigated the effects of habitat loss and fragmentation on sympatric felids (Hunter et al., 2003; Gallas \& da Silveira, 2011), both indirectly.

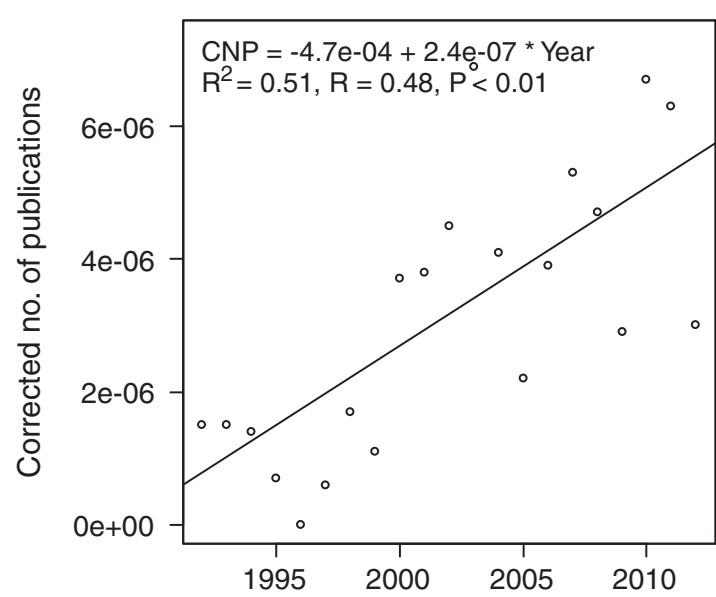

FIG. 2 Linear regression showing relative growth of knowledge about the effects of habitat loss and fragmentation on felids, taking into account the increase in the number of publications in all areas of science. The corrected number of publications (CNP) is the number of publications on the effects of habitat loss and fragmentation on felids, divided by the number of publications indexed on ISI Web of Science.

Studies that consider felids as target species can help elucidate species-specific or taxonomic patterns, which is important given the ecological functions of these species in ecosystems. Felids are the top predators in many ecosystems (Ritchie \& Johnson, 2009) and their extirpation could affect community structure through mesopredator release, resulting in an increase in the abundance of small predators, a decline in prey populations, and species extinctions (Prugh et al., 2009).

Felids may occupy partially overlapping niches, resulting in competition for available habitat and resources (Caro \& Stoner, 2003; Foster et al., 2010). Habitat loss and fragmentation can favour certain species, depending on the predominant matrix type, as species differ in their environmental plasticity and their ability to use suboptimal habitat. Thus, we expect that land-cover change alters the competitive relationship among sympatric felids. However, despite its relevance for felid conservation planning, this topic remains unexplored (Fig. 3).

Characteristics of habitat loss and fragmentation evaluated The themes investigated most frequently were the effects of habitat reduction or subdivision on species (Fig. 1c). Only a few studies addressed exclusively the effects of human infrastructures on felids, and the least studied topic was habitat loss as a result of climate change (Fig. 1c). According to the IUCN Red List (IUCN, 2011), habitat loss and fragmentation affects all 36 wild felid species and is a primary threat for 21 of these. Currently, climate change does not represent a threat to felid species (IUCN, 2011) but few studies have focused on the synergies between climate change and habitat loss for felids (Fig. 3), and therefore 


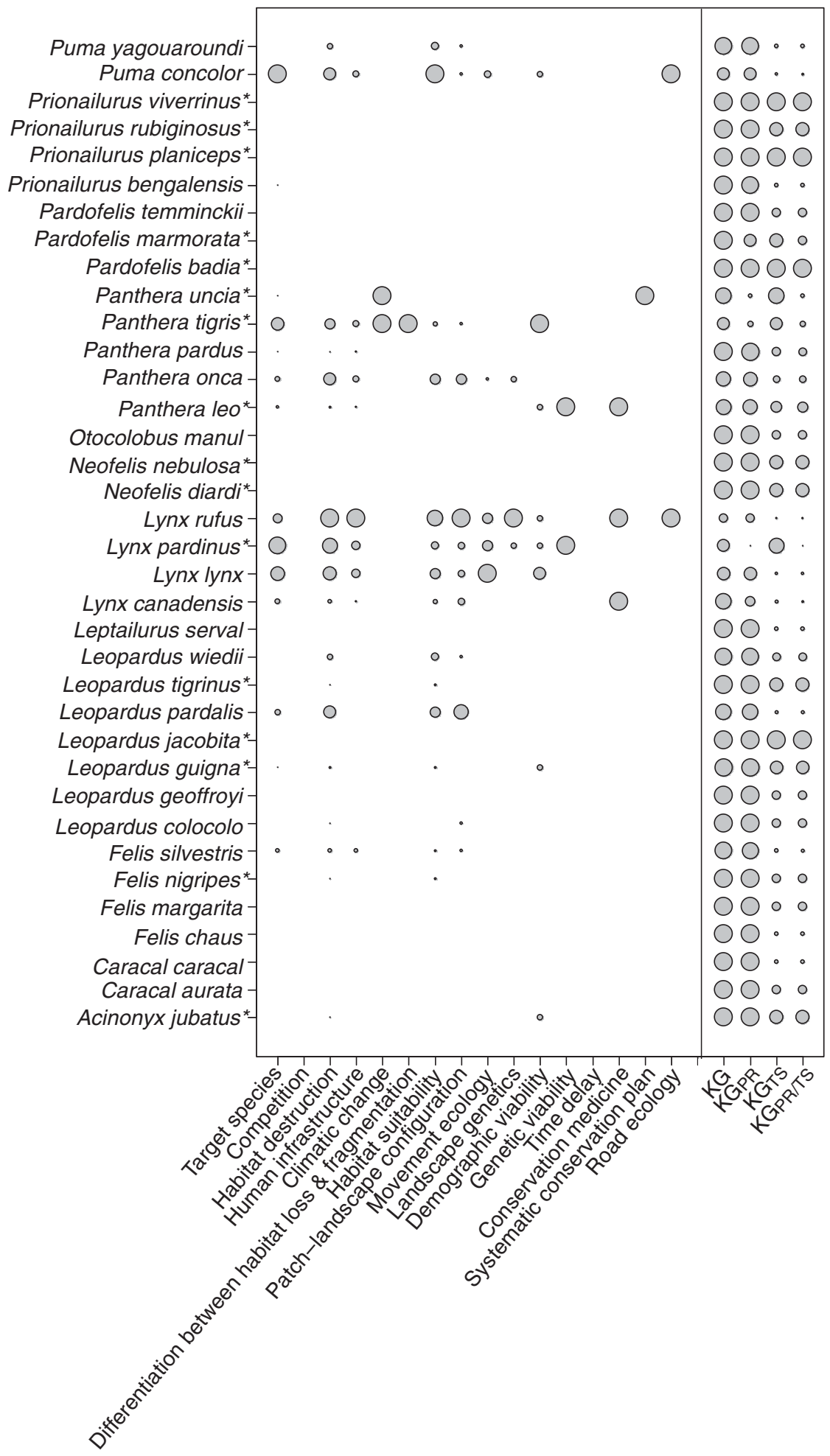

FIG. 3 The state of knowledge of the effects of habitat loss and fragmentation on felid species, based on the number of published scientific articles that evaluate directly these effects. The number of articles was linearly transformed to a scale of o (without circle) to 1 (largest circle). The topics considered were as follows: one target species; the competitive relationship between sympatric felids; effects of habitat destruction; human infrastructure (roads, dams, buildings and other physical barriers); habitat loss as a result of climatic change; differentiation between the effects of habitat loss and fragmentation; habitat suitability; patchlandscape configuration; movement ecology; landscape genetics; demographic viability; genetic viability; time delay of response to habitat loss and fragmentation; conservation medicine; systematic conservation plan; road ecology. These topics were summarized according to indexes that express the knowledge gap: KG, basic knowledge gap index; $\mathrm{KG}_{\mathrm{PR}}$, knowledge gap weighted by the proportion of the species' range unstudied; $\mathrm{KG}_{\mathrm{TS}}$, knowledge gap weighted by values hierarchically distributed to represent threat status (Least Concern, 0.2; Near Threatened, 0.4; Vulnerable, o.6; Endangered, o.8; Critically Endangered, 1.0); $\mathrm{KG}_{\mathrm{PR} / \mathrm{TS} \text {, }}$ knowledge gap weighted by both the proportion of range unstudied and the threat status. ${ }^{\star}$ Threatened species (i.e. Vulnerable, Endangered or Critically Endangered). our comprehension of the issue is incomplete (Heller \& Zavaleta, 2009).

Methodological approach There is a clear bias towards empirical approaches (Fig. 1d) but the imbalance between theoretical and empirical approaches does not constitute a gap in the literature. It is possible to generate good data and generalizations using both approaches but it would be useful to have theoretical approaches that provide testable hypotheses (McGarigal \& Cushman, 2002).

Theoretical studies are useful in situations where manipulation of large-bodied, wide-ranging species is impossible, for ethical or logistical reasons. Such studies can be used to simulate species' responses in a range of 
environmental conditions, and as a basis for empirical studies.

Only three manipulative studies were identified. Reed (2004) investigated the effects of habitat loss and fragmentation on populations of various species, evaluating the importance of dispersal among subpopulations for longterm survival. Brook et al. (2002) investigated the effects of habitat loss and fragmentation but in the context of inbreeding depression, which increases the risk of extinction. Tian et al. (2011) used field data to investigate the effects of habitat loss and fragmentation on the long-term survival of the Amur tiger Panthera tigris altaica. The objective of these studies was to simulate species' responses in different environmental conditions but none used a theoretical approach to improve the design of empirical studies.

Differentiation between habitat loss and fragmentation To differentiate between the processes of habitat loss and fragmentation, landscape-scale studies and true replicates are needed (McGarigal \& Cushman, 2002) but most studies were conducted at the local scale. Only one article distinguished between the two processes (Tian et al., 2011; Fig. 3). It is difficult to define landscape boundaries and independent replicates, especially for species able to disperse widely such as felids. Theoretical approaches could facilitate differentiation between habitat loss and fragmentation for some species through modelling of hypothetical landscapes.

Many articles discussed the use of movement corridors as a mechanism to maintain or reestablish population dynamics (e.g. Carroll \& Miquelle, 2006; Hetherington et al., 2008; Morrison \& Boyce, 2009) and to solve or minimize the problem of fragmentation. Corridors may be an appropriate conservation strategy for felids, given their need for large and connected areas of habitat (Boitani et al., 2011), but they can also leave species at risk of contracting contagious diseases from domestic animals and from retaliatory hunting in human-predator-prey conflicts (Chetkiewicz et al., 2006). Only a few articles evaluated the function of corridors in felid conservation (Fig. 1e). We believe this topic needs more attention, to determine the effects of corridors and which species could benefit from such a strategy.

The design and evaluation of corridors should be based on species dispersal data but should also consider differences according to sex, age, and spatial and temporal scales. Spatial data are relatively frequent among the reviewed publications (Fig. if) but are explored adequately for only a few species (Fig. 3).

Only a few articles made a clear distinction between the processes of habitat loss and fragmentation, and habitat fragmentation was commonly used to represent both processes (Fig. 1g). The felid-research community was slow to adopt the terminology defined by Andrén (1994).

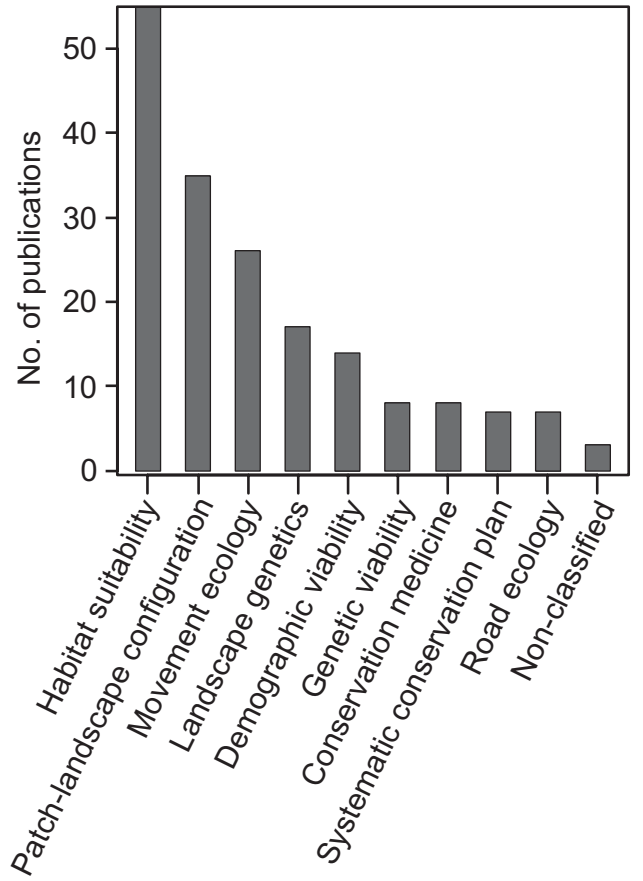

FIG. 4 Number of publications in each sub-discipline (Table 1) considered in this study.

Knowledge of sub-disciplines Knowledge of habitat loss and fragmentation is concentrated in several sub-disciplines: habitat selection and patch-landscape configuration accounted for $56 \%$ of all reviewed publications (Fig. 4). Puma Puma concolor and bobcat Lynx rufus were the focal species in $44 \%$ of habitat selection studies (Fig. 3 ) and had similar responses to habitat loss and fragmentation, including the ability to use landscapes with some level of anthropogenic disturbance (Burdett et al., 2010; Johnson et al., 2010; Supplementary Table S2). Puma, bobcat, and ocelot Leopardus pardalis were the focus of $48 \%$ of articles on patch-landscape configuration (Fig. 3).

Knowledge of movement ecology is fundamental to understanding spatial dynamics at the landscape level, which is a key aspect of the conservation of large-bodied wide-ranging species. This has been explored only for the Iberian lynx Lynx pardinus, through studies of habitat selection on dispersal phases (Palomares et al., 2000), landscape structure (Ferreras et al., 2001), and effects of matrix heterogeneity on dispersal (Revilla et al., 2004). There are also many articles about the movement ecology of the Eurasian lynx Lynx lynx and the bobcat (Fig. 3) but they are not as comprehensive as the studies on the Iberian lynx.

Landscape genetics has been investigated for many species (Fig. 3), yielding conclusions about the effects of habitat loss and fragmentation on population genetic structure (Ernest et al., 2003; Janečka et al., 2008; Schmidt et al., 2011), inbreeding depression (Björklund, 2003; Johnson et al., 2004; Loxterman, 2011), and the long-term 
consequences of genetic diversity loss (Schnitzler, 2011; Singh \& Gibson, 2011). Landscape genetics has become more popular in research than demographic and genetic viability (Figs 3 \& 4). Studies on the effects of habitat loss and fragmentation on population genetics are relevant, given the length of time required to gather demographic data, and the time lags in population responses (Jackson \& Sax, 2010; Krauss et al., 2010). However, no articles reported the time delay of response to habitat loss and fragmentation (Fig. 3). Additionally, there is difficulty in "putting the "landscape" in landscape genetics' (Storfer et al., 2007) because the majority of such studies are based on population genetics and only make indirect inferences regarding habitat loss and fragmentation.

Conservation medicine is the only sub-discipline with a higher number of species than publications (Deem et al., 2001; Aguirre \& Tabor, 2008). However, there remains a lack of field data (Fig. 3), probably because of the interdisciplinary nature of conservation medicine studies, with combined landscape ecology and veterinary approaches.

The least studied disciplines are systematic conservation planning and road ecology (Fig. 4). The selection of priority areas for felid conservation can be difficult because studies of habitat loss and fragmentation are conducted mainly at the local or landscape scale, whereas site-selection studies are commonly carried out at a macroecological scale (Loyola et al., 2009; Mortelliti et al., 2010; Rondinini et al., 2011). Consequently, considering habitat loss and fragmentation in selecting priority areas for felid conservation may be challenging, especially if connectivity and dispersal data are included (Crooks et al., 2011; Hodgson et al., 2011; Lourival et al., 2011). Road ecology studies attempt to quantify the effects of vehicle collisions on animals. Only a few studies have quantified the relationship between traffic, mortality, and population effects (Kerley et al., 2002; Riley et al., 2006; Schwab \& Zandbergen, 2011). Roadkill threatens some felid species (Fig. 3; Supplementary Table S2) but the studies are not focused on these species (Supplementary Table S2).

\section{Allocation of research effort}

The allocation of research effort is unevenly distributed: $>80 \%$ of published studies focus on only seven felid species, and 11 species have not yet been studied (Fig. 3). Allocation of effort was not motivated by conservation priorities, as the number of publications was not correlated with threat status or range contraction (Table 2). Five threatened species do not feature in any articles on habitat loss and fragmentation; this number increases to eight of we consider only studies that were directly focused on the effects of habitat loss and fragmentation (Fig. 3). Of the five felids for which significant range contraction has been recorded (Morrison et al., 2007), three have been poorly
TABLE 2 Summary of variables' predictive power to describe the allocation of research effort for articles about the effects of habitat loss and fragmentation on felids.

\begin{tabular}{lcc}
\hline Effect & df & $F$ \\
\hline Intercept & 1 & 2.31 \\
IUCN threat status & 4 & 2.18 \\
Body size & 1 & $10.78^{*}$ \\
Range size & 1 & $<0.01$ \\
Total habitat area & 1 & 0.38 \\
Proportion of habitat in the range & 1 & 0.29 \\
Error & 27 & \\
\hline
\end{tabular}

${ }^{\star} \mathrm{P}<0.05$

studied in terms of habitat loss and fragmentation (lion Panthera leo, leopard Panthera pardus and cheetah Acinonyx jubatus; Fig. 3).

We expected to find more publications on species with larger distributions, given that researchers have greater options for selecting sites to study such species, but our findings did not support this prediction (Table 2). Rather, we found that large-bodied felids are more studied (Table 2), suggesting that choice of research subject may be motivated by charismatic characteristics rather than conservation priorities (Brodie, 2009). Another explanation could be the ease of studying large felids by camera trapping, as larger animals are more likely to be detected by sensors (Karanth et al., 2004), and the coat patterns used to identify individuals (Karanth et al., 2006) are more common in large cats (Brodie, 2009). However, camera-trapping techniques were used in only a few studies (Fig. 1) and therefore do not account for the difference in research effort allocated to large and small felids.

The allocation of research effort in studies of the effects of habitat loss and fragmentation on felids is also disproportional across countries, with research concentrated in countries with greater economic development (Fig. 5; Supplementary Fig. S1). Studies in countries with less economic development were frequently conducted by a local researcher but it was common for them to have coresearchers from countries with greater economic development (Fig. 6). This result shows a collaborative relationship between researchers from different countries, which may be motivated by the higher financial support for research provided by developed countries, and the knowledge gap in less developed areas.

\section{Knowledge-gap analysis}

A considerable knowledge gap exists regarding the effects of habitat loss and fragmentation on many felid species (Fig. 3). Only the bobcat has been adequately studied in the context of the majority of issues (Fig. 3). For 16 species there is no information available about how they are affected 

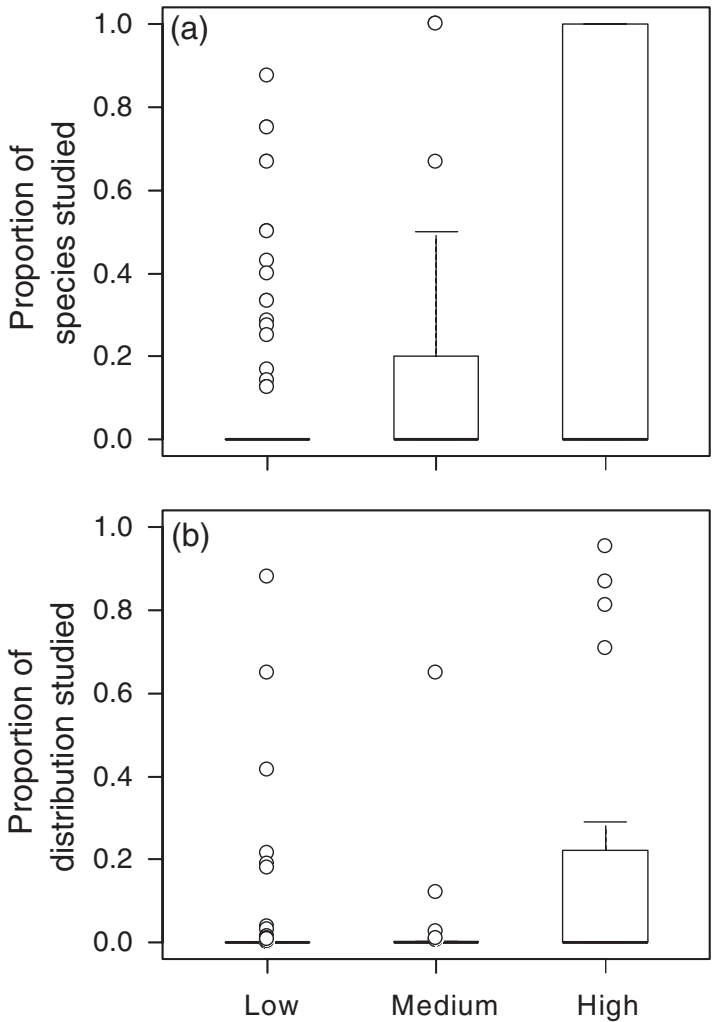

FIG. 5 Comparison of research effort between countries with low ( $\leqslant 10$ times the income needed to live at the poverty line), medium $(>10$ and $\leqslant 30$ times) and high $(>30$ times) annual gross national income per capita (see text for details). The research effort is expressed as (a) the proportion of felid species studied relative to the number of felid species in a country (Kruskal-Wallis test: $\chi^{2}=12.56, \mathrm{P}<0.01$; Nemenyi test for low and high classes: $\mathrm{P}=0.01$ ) and (b) the proportion of the species' range studied (Kruskal-Wallis test: $\chi^{2}=10.98, \mathrm{P}<0.01$; Nemenyi test for low and high classes: $\mathrm{P}=0.04$ ).

by habitat loss and fragmentation. The inclusion of proportion of range studied decreases the knowledge gap for species that are the focus of theoretical studies (Forrest et al., 2012; Trisurat et al., 2012; Fig. 3). After weighting species by threat status there are four species for which larger knowledge gaps exist (the Andean mountain cat Leopardus jacobita, the Bornean bay cat Pardofelis badia, the flat-headed cat Prionailurus planiceps and the fishing cat Prionailurus viverrinus; Fig. 3).

\section{Conclusions}

Our analyses indicate that the knowledge gap concerning the effects of habitat loss and fragmentation on felids varies considerably among species. Larger-scale investigations are needed to improve the conservation of this group. Knowledge gaps could be addressed by focusing on approaches such as (1) differentiation of habitat loss from fragmentation effects using theoretical scenarios,

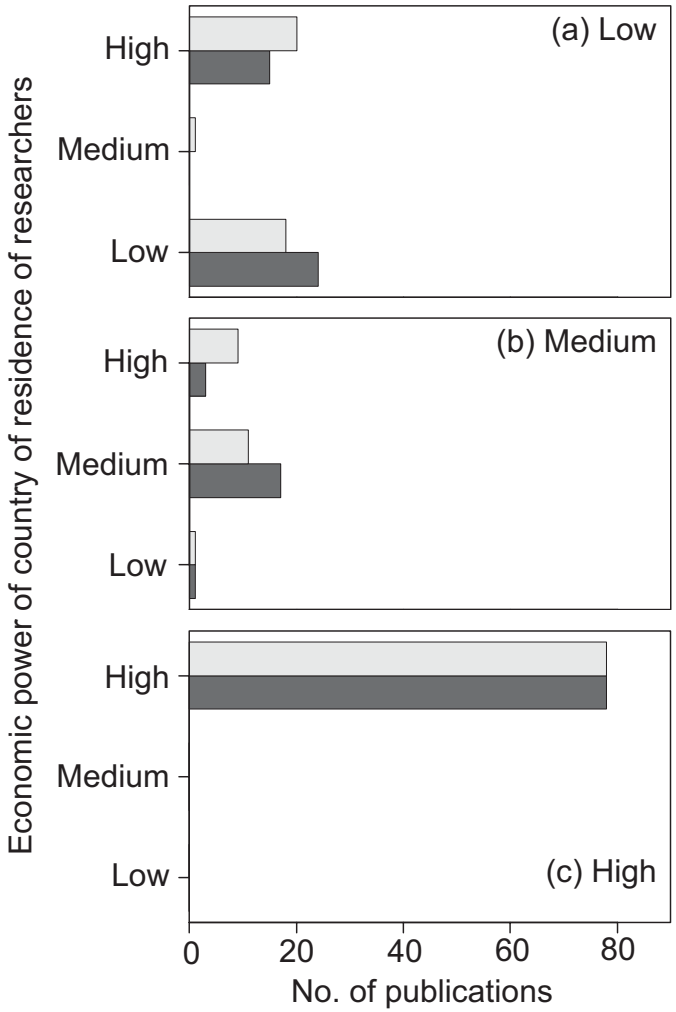

FIG. 6 The number of publications on the effects of habitat loss and fragmentation on felids, according to the economic power (high, medium or low) of the country of residence of researchers. The publications are categorized according the gross national income per capita of the country where the study was carried out: (a) low, $\leqslant 10$ times the income needed to live at the poverty line; (b) medium, $>10$ and $\leqslant 30$ times; (c) high, $>30$ times. Dark grey represents the nationality of the first author and light grey represents the nationality of the author from the most developed country.

(2) selection of priority areas for conservation, considering land-cover types and configuration on a range-wide scale, and (3) investigating the consequences of habitat loss and/or changes as a result of climate change. These are not the only potential fields of investigation that could improve our understanding of the effects of habitat loss and fragmentation on felids, but these three approaches would facilitate the identification of general patterns and cover a large portion of species' ranges.

We found that research had a predominantly zoological emphasis, with most published articles describing speciesspecific or local attributes. Few articles included ecological theories within their scope. Felid conservationists must start to design more theoretically sound projects, and apply the new tools and methodologies that are available in landscape and wildlife research. The local approach is important for species conservation but felid research also needs a broader scale approach to improve the conservation of this important component of biodiversity. 


\section{References}

Aguirre, A. \& Tabor, G.M. (2008) Global factors driving emerging infectious diseases. Annals of the New York Academy of Sciences, 1149, 1-3.

Amori, G. \& Gippoliti, S. (2000) What do mammalogists want to save? Ten years of mammalian conservation biology. Biodiversity and Conservation, 9, 785-793.

ANDrén, H. (1994) Effects of habitat fragmentation on birds and mammals in landscapes with different proportions of suitable habitat: a review. Oikos, 71, 355-366.

BJÖRKLUND, M. (2003) The risk of inbreeding due to habitat loss in the lion (Panthera leo). Conservation Genetics, 4, 515-523.

Boitani, L., Maiorano, L., Baisero, D., Falcucci, A., Visconti, P. \& Rondinini, C. (2011) What spatial data do we need to develop global mammal conservation strategies? Philosophical Transactions of the Royal Society of London B, 366, 2623-2632.

BRODIE, J.F. (2009) Is research effort allocated efficiently for conservation? Felidae as a global case study. Biodiversity and Conservation, 18, 2927-2939.

Brook, B.W., Tonkyn, D.W., O’Grady, J.J. \& Frankham, R. (2002) Contribution of inbreeding to extinction risk in threatened species. Conservation Ecology, 6, 1-11.

Burdett, C.L., Crooks, K.R., Theobald, D.M., Wilson, K.R., Boydston, E.E., Lyren, L.M. et al. (2010) Interfacing models of wildlife habitat and human development to predict the future distribution of puma habitat. Ecosphere, 1, 1-21.

Caro, T. \& Stoner, C. (2003) The potential for interspecific competition among African carnivores. Biological Conservation, 110, $67-75$.

Carroll, C. \& Miquelle, D.G. (2006) Spatial viability analysis of Amur tiger Panthera tigris altaica in the Russian Far East: the role of protected areas and landscape matrix in population persistence. Journal of Applied Ecology, 43, 1056-1068.

Chetkiewicz, C.-L.B., St. Clair, C.C. \& Boyce, M.S. (2006) Corridors for conservation: integrating pattern and process. Annual Review of Ecology, Evolution, and Systematics, 37, 317-342.

Crooks, K.R., Burdett, C.L., Theobald, D.M., Rondinini, C. \& BoITANI, L. (2011) Global patterns of fragmentation and connectivity of mammalian carnivore habitat. Philosophical Transactions of the Royal Society of London B, 366, 2642-2651.

Davidson, A.D., Hamilton, M.J., Boyer, A.G., Brown, J.H. \& Ceballos, G. (2009) Multiple ecological pathways to extinction in mammals. Proceedings of the National Academy of Sciences of the United States of America, 106, 10702-10705.

Debinski, D.M. \& Holt, R.D. (200o) A survey and overview of habitat fragmentation experiments. Conservation Biology, 14, 342-355.

Deem, S.L., Karesh, W.B. \& Weisman, W. (2001) Putting theory into practice: wildlife health in conservation. Conservation Biology, $15,1224-1233$.

Ernest, H., Boyce, W., Bleich, V., May, B., Stiver, S.J. \& Torres, S.G. (2003) Genetic structure of mountain lion (Puma concolor) populations in California. Conservation Genetics, 4, 353-366.

ESA (European Space Agency) (2011) GlobCover. Http://due.esrin. esa.int/globcover/ [accessed 8 May 2014].

Ewers, R.M. \& Didham, R.K. (2006) Confounding factors in the detection of species responses to habitat fragmentation. Biological Reviews, 81, 117-142.

FAHRIG, L. (1997) Relative effects of habitat loss and fragmentation on population extinction. The Journal of Wildife Management, 61, 603-610.
FAHRIG, L. (2003) Effects of habitat fragmentation on biodiversity. Annual Review of Ecology, Evolution, and Systematics, 34, 487-515.

Ferreras, P., Aldama, J.J., Beltrán, J.F. \& Delibes, M. (1992) Rates and causes of mortality in a fragmented population of Iberian lynx Felis pardina Temminck, 1824. Biological Conservation, 61, 197-202.

Ferreras, P., Gaona, P., Palomares, F. \& Delibes, M. (2001) Restore habitat or reduce mortality? Implications from a population viability analysis of the Iberian lynx. Animal Conservation, 4, 265-274.

Fischer, J. \& Lindenmayer, D.B. (2007) Landscape modification and habitat fragmentation: a synthesis. Global Ecology and Biogeography, $16,265-280$.

Foley, J.A., DeFries, R., Asner, G.P., Barford, C., Bonan, G., Carpenter, S.R. et al. (2005) Global consequences of land use. Science, 309, 570-574.

Forrest, J.L., Wikramanayake, E., Shrestha, R., Areendran, G., Gyeltshen, K., Maheshwari, A. et al. (2012) Conservation and climate change: assessing the vulnerability of snow leopard habitat to treeline shift in the Himalaya. Biological Conservation, 150, 129-135.

Foster, R.J., Harmsen, B.J. \& Doncaster, C.P. (2010) Habitat use by sympatric jaguars and pumas across a gradient of human disturbance in Belize. Biotropica, 42, 724-731.

Gallas, M. \& Da Silveira, E.F. (2011) Mesocestoides sp. (Eucestoda, Mesocestoididae) parasitizing four species of wild felines in southern Brazil. Revista Brasileira de Parasitologia Veterinaria de Jaboticabal, 20, 168-170.

Haila, Y. (2002) A conceptual genealogy of fragmentation research: from island biogeography to landscape ecology. Ecological Applications, 12, 321-334.

Heller, N.E. \& Zavaleta, E.S. (2009) Biodiversity management in the face of climate change: a review of 22 years of recommendations. Biological Conservation, 142, 14-32.

Hetherington, D.A., Miller, D.R., Macleod, C.D. \& Gorman, M.L. (2008) A potential habitat network for the Eurasian lynx Lynx lynx in Scotland. Mammal Review, 38, 285-303.

Hodgson, J.A., Moilanen, A., Wintle, B.A. \& Thomas, C.D. (2011) Habitat area, quality and connectivity: striking the balance for efficient conservation. Journal of Applied Ecology, 48, 148-152.

Hunter, R.D., Fisher, R.N. \& Crooks, K.R. (2003) Landscape-level connectivity in coastal southern California, USA, as assessed through carnivore habitat suitability. Natural Areas Journal, 23, 302314.

Inskip, C. \& Zimmermann, A. (2009) Human-felid conflict: a review of patterns and priorities worldwide. Oryx, 43, 18-34.

IUCN (2011) IUCN Red List of Threatened Species v. 2011.1. Http://www.iucnredlist.org/ [accessed 8 May 2014].

JACKSON, S.T. \& SAX, D.F. (2010) Balancing biodiversity in a changing environment: extinction debt, immigration credit and species turnover. Trends in Ecology \& Evolution, 25, 153-160.

JanečKa, J.E., Tewes, M.E., LAack, L.L., Grassman, L.I., Haines, A. M. \& Honeycutt, R.L. (2008) Small effective population sizes of two remnant ocelot populations (Leopardus pardalis albescens) in the United States. Conservation Genetics, 9, 869-878.

Jenkins, D.G., Brescacin, C.R., Duxbury, C.V., Elliott, J.A., Evans, J.A., Grablow, K.R. et al. (2007) Does size matter for dispersal distance? Global Ecology and Biogeography, 16, 415-425.

Johnson, S.A., Walker, H.D. \& Hudson, C.M. (2010) Dispersal characteristics of juvenile bobcats in South-Central Indiana. The Journal of Wildlife Management, 74, 379-385. 
Johnson, W.E., Eizirik, E., Pecon-Slattery, J., Murphy, W.J., Antunes, A., Teeling, E. \& O'Brien, S.J. (2006) The late Miocene radiation of modern Felidae: a genetic assessment. Science, 311, 73-77.

Johnson, W.E., Godoy, J.A., Palomares, F., Delibes, M., Fernandes, M., Revilla, E. \& O’Brien, S.J. (2004) Phylogenetic and phylogeographic analysis of Iberian lynx populations. Journal of Heredity, 95, 19-28.

Karanth, K.U., Nichols, J.D., Kumar, N.S. \& Hines, J.E. (2006) Assessing tiger population dynamics using photographic capture-recapture sampling. Ecology, 87, 2925-2937.

Karanth, K.U., Nichols, J.D., Kumar, N.S., Link, W.A. \& Hines, J.E. (2004) Tigers and their prey: predicting carnivore densities from prey abundance. Proceedings of the National Academy of Sciences of the United States of America, 101, 4854-4858.

Kerley, L.L., Goodrich, J.M., Miquelle, D.G., Smirnov, E.N., Quigley, H.B. \& HorNocker, M.G. (2002) Effects of roads and human disturbance on Amur tigers. Conservation Biology, $16,97-108$.

Krauss, J., Bommarco, R., Guardiola, M., Heikkinen, R.K., Helm, A., Kuussaari, M. et al. (2010) Habitat fragmentation causes immediate and time-delayed biodiversity loss at different trophic levels. Ecology Letters, 13, 597-605.

Lord, J.M. \& Norton, D.A. (1990) Scale and the spatial concept of fragmentation. Conservation Biology, 4, 197-202.

Lourival, R., Drechsler, M., Watts, M.E., Game, E.T. \& Possingham, H.P. (2011) Planning for reserve adequacy in dynamic landscapes; maximizing future representation of vegetation communities under flood disturbance in the Pantanal wetland. Diversity and Distributions, 17, 297-310.

Loxterman, J.L. (2011) Fine scale population genetic structure of pumas in the Intermountain West. Conservation Genetics, 12, 1049-1059.

Loyola, R.D., Oliveira-Santos, L.G.R., Almeida-Neto, M., Nogueira, D.M., Kubota, U., Diniz-Filho, J.A.F. \& LEWINSOHN, T.M. (2009) Integrating economic costs and biological traits into global conservation priorities for carnivores. PLoS ONE, 4(8), e6807.

McGarigal, K. \& Cushman, S.A. (2002) Comparative evalution of experimental approaches to the study of habitat fragmentation effects. Ecological Applications, 12, 335-345.

Morales, M.M. \& Giannini, N.P. (2010) Morphofunctional patterns in Neotropical felids: species co-existence and historical assembly. Biological Journal of the Linnean Society, 100, 711-724.

Morrison, J.C., Sechrest, W., Dinerstein, E., Wilcove, D.S. \& Lamoreux, J.F. (2007) Persistence of large mammal faunas as indicators of global human impacts. Journal of Mammalogy, $88,1363-1380$.

Morrison, S.A. \& Boyce, W.M. (2009) Conserving connectivity: some lessons from mountain lions in southern California. Conservation Biology, 23, 275-285.

Mortelliti, A., Amori, G., Capizzi, D., Rondinini, C. \& Boitani, L. (2010) Experimental design and taxonomic scope of fragmentation studies on European mammals: current status and future priorities. Mammal Review, 40, 125-154.

Öckinger, E., Schweiger, O., Crist, T.O., Debinski, D.M., Krauss, J., KuUssaari, M. et al. (2010) Life-history traits predict species responses to habitat area and isolation: a cross-continental synthesis. Ecology Letters, 13, 969-979.

Palomares, F., Delibes, M., Ferreras, P., Fedriani, J.M., Calzada, J. \& Revilla, E. (2000) Iberian lynx in a fragmented landscape: predispersal, dispersal, and postdispersal habitats. Conservation Biology, 14, 809-818.
Prugh, L.R., Stoner, C.J., Epps, C.W., Bean, W.T., Ripple, W.J., Laliberte, A.S. \& Brashares, J.S. (2009) The rise of the mesopredator. BioScience, 59, 779-791.

Ravallion, M., Chen, S. \& Sangraula, P. (2009) Dollar a day revisited. The World Bank Economic Review, 23, 163-184.

Reed, D.H. (2004) Extinction risk in fragmented habitats. Animal Conservation, 7, 181-191.

Revilla, E., Wiegand, T., Palomares, F., Ferreras, P. \& Delibes, M. (2004) Effects of matrix heterogeneity on animal dispersal: from individual behavior to metapopulation-level parameters. The American Naturalist, 164, E130-E153.

Riley, S.P.D., Pollinger, J.P., Sauvajot, R.M., York, E.C., Bromley, C., Fuller, T.K. \& Wayne, R.K. (2006) A southern California freeway is a physical and social barrier to gene flow in carnivores. Molecular Ecology, 15, 1733-1741.

Ritchie, E.G. \& Johnson, C.N. (2009) Predator interactions, mesopredator release and biodiversity conservation. Ecology Letters, 12, 982-998.

Rittters, K., Wickham, J., O’Neill, R., Jones, B. \& Smith, E. (2000) Global-scale patterns of forest fragmentation. Conservation Ecology, 4, 3.

Rodríguez, A. \& Delibes, M. (1992) Current range and status of the Iberian lynx Felis pardina Temminck, 1824 in Spain. Biological Conservation, 61, 189-196.

Rondinini, C., Di Marco, M., Chiozza, F., Santulli, G., Baisero, D., Visconti, P. et al. (2011) Global habitat suitability models of terrestrial mammals. Philosophical Transactions of the Royal Society of London B, 366, 2633-2641.

Schmidt, K., Ratikiewicz, M. \& Konopínski, M.K. (2011) The importance of genetic variability and population differentiation in the Eurasian lynx Lynx lynx for conservation, in the context of habitat and climate change. Mammal Review, 41, 112-124.

Schnitzler, A.E. (2011) Past and present distribution of the North African-Asian lion subgroup: a review. Mammal Review, $41,220-243$.

Schwab, A.C. \& Zandbergen, P.A. (2011) Vehicle-related mortality and road crossing behavior of the Florida panther. Applied Geography, 31, 859-870.

Singh, H.S. \& Gibson, L. (2011) A conservation success story in the otherwise dire megafauna extinction crisis: the Asiatic lion (Panthera leo persica) of Gir forest. Biological Conservation, 144, 1753-1757.

Storfer, A., Murphy, M.A., Evans, J.S., Goldberg, C.S., Robinson, S., Spear, S.F. et al. (2007) Putting the 'landscape' in landscape genetics. Heredity, 98, 128-142.

Sunquist, M. \& Sunquist, F. (2002) Wild Cats of the World. The University of Chicago Press, Chicago, USA.

Thornton, D., Branch, L. \& Sunquist, M. (2011) Passive sampling effects and landscape location alter associations between species traits and response to fragmentation. Ecological Applications, 21, $817-829$.

Tian, Y., Wu, J., Smith, A.T., Wang, T., Kou, X. \& Ge, J. (2011) Population viability of the Siberian Tiger in a changing landscape: going, going and gone? Ecological Modelling, 222, 3166-3180.

Trisurat, Y., Bhumpakphan, N., Reed, D.H. \& Kanchanasaka, B. (2012) Using species distribution modeling to set management priorities for mammals in northern Thailand. Journal for Nature Conservation, 20, 264-273.

Watling, J.I., Nowakowski, A.J., Donnelly, M.A. \& Orrock, J.L. (2011) Meta-analysis reveals the importance of matrix composition for animals in fragmented habitat. Global Ecology and Biogeography, 20, 209-217. 
Wilson, D.E. \& Reeder, D.M. (2005) Mammal Species of the World. A Taxonomic and Geographic Reference, 3rd edition. Johns Hopkins University Press, Baltimore, USA.

Woodroffe, R. \& GinsberG, J.R. (1998) Edge effects and the extinction of populations inside protected areas. Science, 280 , $2126-2128$

World BANK (2010) Global Economy: GNI per capita 2000-2009, Atlas Method. Http://www.geohive.com/charts/ec_gni1.aspx [accessed 9 May 2014].

ZAR, J.H. (2010) Biostatistical Analysis, 5th edition. Prentice Hall, Upper Saddle River, USA.

\section{Biographical sketches}

MARINA ZANIN is interested in studying felids in the context of landscape ecology, theoretical ecology and conservation biology. Francisco Palomares is interested in the ecology and conservation biology of vertebrates and has studied several European and American species of predators and their prey, using both invasive and noninvasive sampling techniques. D ANIEL BRITO's research focus is on comprehending the extinction process, identifying conservation priorities, advancing Red Lists as conservation tools, and estimating the consequences of knowledge gaps in conservation. 